\title{
Low-field NMR for quality control on oils
}

\author{
Thomas Rudszuck $^{1}$ (D) | Eva Förster ${ }^{1}$ | Hermann Nirschl ${ }^{1}$ (D) | Gisela Guthausen ${ }^{1,2}$ (D)
}

\author{
${ }^{1}$ Institute for Mechanical Engineering and \\ Mechanics, Karlsruher Institute of \\ Technology (KIT), Karlsruhe, Germany \\ ${ }^{2}$ Engler-Bunte Institute, Water Science \\ and Technology, Karlsruher Institute of \\ Technology (KIT), Karlsruhe, Germany

\section{Correspondence \\ Gisela Guthausen, MVM and WCT, KIT, 76131 Karlsruhe, Germany. \\ Email: gisela.guthausen@kit.edu \\ Funding information \\ AiF Arbeitsgemeinschaft industrieller Forschungsvereinigungen "Otto von \\ Guericke" e.V.; Deutsche \\ Forschungsgemeinschaft; Zentrales \\ Innovationsprogramm Mittelstand (ZIM)}

\begin{abstract}
Oil is a prominent, but multifaceted material class with a wide variety of applications. Technical oils, crude oils as well as edibles are main subclasses. In this review, the question is addressed how low-field NMR can contribute in oil characterization as an analytical tool, mainly with respect to quality control. Prerequisite in the development of a quality control application, however, is a detailed understanding of the oils and of the measurement. Low-field NMR is known as a rich methodical toolbox that was and is explored and further developed to address questions about oils, their quality, and usability as raw materials, during production and formulation as well as in use.
\end{abstract}

\section{KEYWORDS}

diffusion, edible fats and oils, low-field NMR, lubricants, PFG-NMR, relaxation, spectroscopy

\section{1 | INTRODUCTION}

Low-field (LF)-NMR has been developed into a powerful and versatile tool over decades, especially for quality control (QC) and process monitoring. The first applications were already described in the 1960s. Due to its relatively simple design compared with high-field instruments, the high reliability and reproducibility and robustness even in harsh enviroments, LF-NMR is becoming indispensable in more an more industrial branches. In conjunction with automated data processing and analysis, a wide variety of processes can be monitored time-resolved and continuously.
The major technical developments of the last tens of years can crudely be classified into two aspects. Singlesided devices, for example, ${ }^{[1]}$ are designed to be as compact, flexible, and light as possible. By using surface coils, almost arbitrarily shaped objects can be analyzed without time-consuming sample preparation. ${ }^{1} \mathrm{H}$ relaxation and/or diffusion measurements allow insight into properties of an object under investigation. The construction facilitates a high sample throughput even in environments difficult to access.

The second development concerns NMR spectroscopy at frequencies up to currently $92 \mathrm{MHz}$. In classic LF-NMR, instruments with increasingly higher magnetic

\footnotetext{
Abbreviations: $B_{0}$, static magnetic field (T); $B_{1}$, radio frequency magnetic field (T); $\delta$, gradient pulse duration (s); $\Delta$, gradient pulse delay, diffusion time (s); $D$, diffusion coefficient $\left(\mathrm{m}^{2} / \mathrm{s}\right) ; \gamma$, gyromagnetic ratio (1/[Ts]); $G$, gradient amplitude (T/m); $M_{2}$, second moment of a quantity; $R_{1}$, longitudinal relaxation rate $(1 / \mathrm{s}) ; R_{2}$, transverse relaxation time $(1 / \mathrm{s}) ; T_{1}$, longitudinal relaxation time $(\mathrm{s}) ; T_{2}$, transverse relaxation time (s); $\omega_{0}$, Larmor angular frequency $(\mathrm{rad} / \mathrm{s}) ; \nu_{0}$, Larmor frequency $(\mathrm{Hz})$; AW, anti wear; COSY, correlation spectroscopy; CPMG, multiecho sequence according to Carr, Purcell, Meiboom, and Gill; CWFP, continuous wave free precession; EP, extreme pressure; EVOO, extra virgin olive oil; FA, fatty acid; FAME, fatty acid methyl ester; FFC, fast field cycling; FID, free induction decay; FTIR, Fourier transform infrared spectroscopy; GCMS, gas chromatography-mass spectrometry; HSQC, heteronuclear single quantum correlation; ICP-OES, inductively coupled plasma optical emission spectrometry; ILT, inverse Laplace transformation; IUPAC, International Union of Pure and Applied Chemistry; LF, low field; MOUSE, mobile universal surface explorer; NMR, nuclear magnetic resonance; O/W, oil-in-water emulsion; PCA, principal component analysis; PFG, pulsed field gradient; PFG-SE, pulsed field gradient spin echo; PFG-STE, pulsed field gradient stimulated echo; PLSR, projection on latent structures regression, also named partial least squares regression; PRE, paramagnetic relaxation enhancement; QC, quality control; SFC, solid fat content; SE, spin echo; STE, stimulated echo; TAG, triacylglycerol; TAN, total acid number; TBN, total base number; TD, time domain; TRDD, transverse relaxation decay deconvolution; VI, viscosity index
} 
fields became available on the market. Until the 1990s, LF-NMR was mainly limited to the investigation of ${ }^{1} \mathrm{H}$ relaxation. Permanent magnets up to $1.9 \mathrm{~T}$ with increasing magnetic field homogeneities ensured that NMR spectroscopy in low magnetic fields has been exploited over the last 20 years. $^{[2-12]}$ The investigation of heteronuclei $\left({ }^{19} \mathrm{~F},{ }^{13} \mathrm{C},{ }^{15} \mathrm{~N}\right.$, and $\left.{ }^{31} \mathrm{P}\right)$ opens up additional perspectives, for example. ${ }^{[13,14]}$

One of the most important applications of LF-NMR concerns the characterization of oils and fats (Table 1). These are present in diverse areas of everyday's life, such as in foods, as fuels or as lubricants. Depending on the application field, oils are exposed to different but specific requirements, which are proofed by LF-NMR, among other valuable analytical techniques. It is necessary to determine various quality parameters already for raw oils, independent of the use of the oils in food, as lubricants or in other applications. These quality parameters are of decisive importance for further processing. Especially in the case of food oils, further processing requires close-meshed QC. In later use, the oil's quality has to be monitored, for example to detect the aging of lubricating oils or product rancidity and falsification of food oils and fats.

According to these requirement profiles, this review on the application of LF-NMR especially in QC of oils will be subdivided into the following sections: Based on the four material classes-crude oils, fuels, lubricating oils, and edible oils-(a) application examples of LF-NMR in the production or extraction of raw materials, (b) in the formation or adjustment of properties, and (c) on oils in use, that is, aging of oils, will be summarized (Figure 1).

\section{TYPES OF OILS AND FATS}

As the chemical and physical variety of "oil" is rather large and therefore unspecific, the substances are crudely classified and defined in the following, before

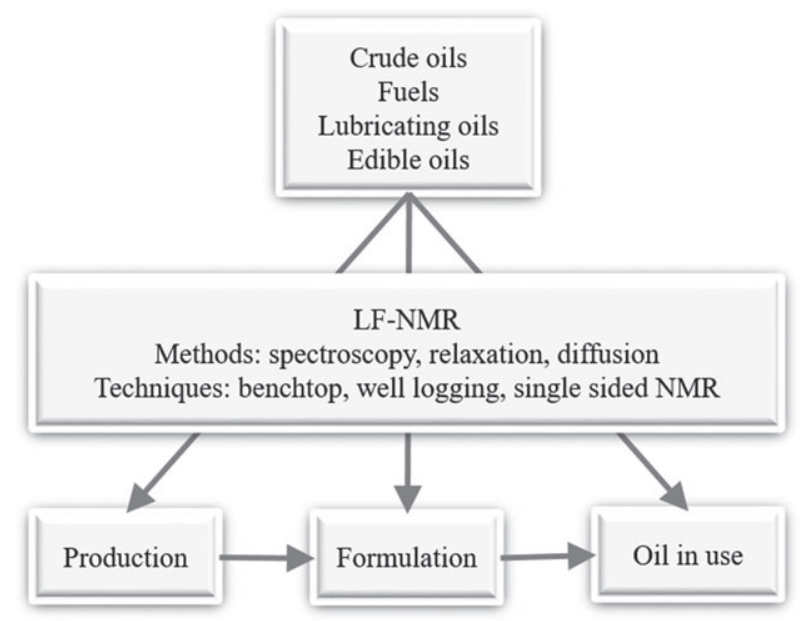

FIGURE 1 Overview of the structure of this review. According to four oil types - crude oils, fuel, lubricating oils, and edible oils, applications of the LF-NMR in the field of production, formulation and in use are discussed (LF: low field)

TABLE 1 Summary of typical applications of LF-NMR on the four oil types — crude oils, fuels, lubricating oils, and edible oil

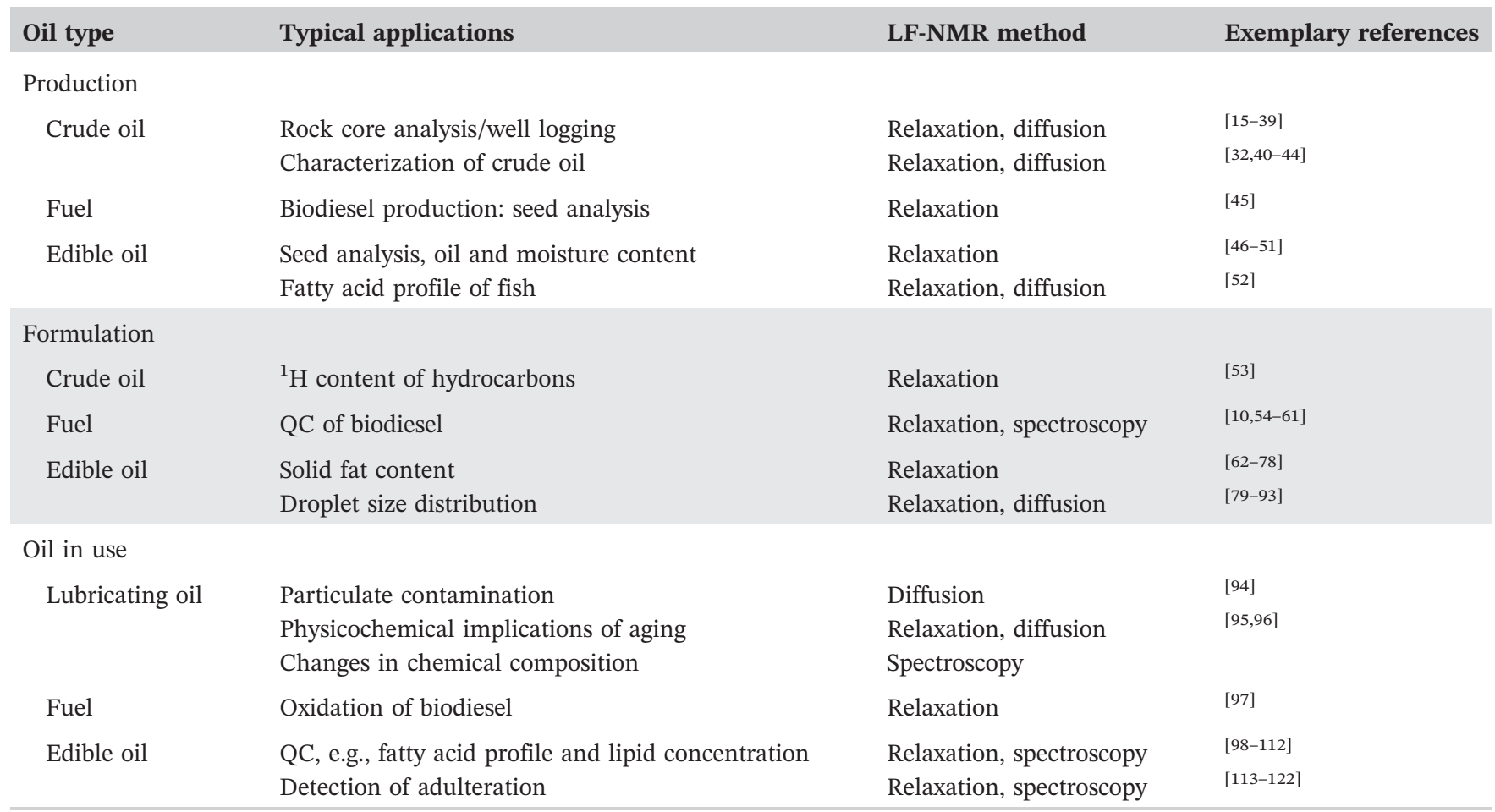

Note. LF: low field; QC: quality control. 
summarizing LF-NMR approaches to analyze and characterize these classes of materials.

\section{1 | Crude oils}

Crude oil is a mixture of diverse chemicals naturally occurring in the upper earth crust. It is mainly composed of hydrocarbons with a variety of molecular weights. Conversion processes of organic matter led to the current crude oil reservoirs. The total content of hydrocarbons in crude oils is in the range of $95-99 \%$. The nonhydrocarbon compounds mostly consist of gum and asphaltenes showing the additional chemical elements $\mathrm{O}, \mathrm{N}$, and $\mathrm{S}^{\left[{ }^{123]}\right.}$ The hydrocarbons in crude oils can roughly be divided into three groups: paraffinic, naphthenic, and aromatic hydrocarbons. Paraffinic hydrocarbons are described by the molecular formula $\mathrm{C}_{\mathrm{n}} \mathrm{H}_{2 \mathrm{n}+2}$. They are $\mathrm{n}$ - and isoalkanes containing saturated, $\mathrm{sp}^{3}$ hybridized chemical bonds. Paraffins are found in natural gas, in liquid oil, and solid petroleum waxes. Typical chain lengths of paraffinic hydrocarbons range from 1 to 70 monomeric units in form of $-\mathrm{CH}_{2}-$ groups. Up to four units, paraffin is gaseous at ambient temperature and atmosphere pressure, from five to 14 monomeric units they are liquids, whereas hydrocarbons with higher numbers of $-\mathrm{CH}_{2}-$ groups are solid at ambient. ${ }^{[123]}$ Naphthenic hydrocarbons show ring or cyclic structures and are chemically as stable as paraffins. A typical representative in the group of naphthenic hydrocarbons is cyclopentane. Aromatic hydrocarbons of the third group contain $\mathrm{C}=\mathrm{C}$ double bonds. As their chemical reactivity is higher, they often tend to oxidize. The other components of crude oil most often have a macromolecular structure. Resins and asphaltenes are typical nonhydrocarbon compounds. The group of asphaltenes is defined by solubility; they tend to agglomerate, whereas the molecular masses are in the range of 400 to $1,500 \mathrm{u}$.

\section{2 | Oils as lubricants}

Wherever surfaces of solid work pieces move relative to each other with small distances, friction, in consequence temperature hot spots and abrasion occur. Lubricants are essential to minimize these effects. A variety of lubricants exists, also due to the variety of applications in gears, bearings, conversions, and motors of all kind. All lubricants consist mainly of a base oil and of additives to a much smaller extent. Additive concentrations range between $1 \%$ and $20 \% .{ }^{[124]}$ Furthermore, base oils mainly are mineral, semisynthetic, or synthetic oils. Mineral oils dominantly consist of hydrocarbons of different molecular size and structure. Two main types are present: aliphatic and aromatic molecular groups.
To improve and design the oil's properties for a given application, semisynthetic oils were developed. They essentially are mineral oils, which have undergone a second refinement step and often consist of a mixture of mineral oil and synthetic oil. Also, cracking is used to form new molecules with the aim of improving dedicated properties of an oil for a specific application.

The most expensive group of base oils are the fully synthetic oils as their molecules are completely reformed to tailor desired application properties. Synthetic base oils are poly-alpha-olefins and esters for example. ${ }^{[125]}$ In order to finally optimize the application dependent properties of the lubricants, additives are added. Additives most often are synthetic chemicals and influence the physical and chemical properties of the lubricants especially on the long term. Typical additives determining the chemical and physical properties are, for example, antioxidants reducing the otherwise evolving acidity. Others, such as extreme pressure or anti wear additives form films on the mainly metallic surfaces. These compounds often contain sulfur and phosphorus, for instance, in form of triphenyl phosphorotionate and zinc dialkyldithiophosphate. Physical properties like viscosity can be influenced, for example, by viscosity index improvers, whose chemical composition depends on the application's temperature. ${ }^{[126,127]}$

\section{3 | Diesel/biodiesel}

An alternative to petroleum based diesel, ${ }^{[128,129]}$ being produced by distillation of crude oil, is biodiesel. It became increasingly important but is also controversially discussed. Biodiesel is distinguished by its good biodegradability, renewability, low toxicity, and total lowemission profile. Typically, biodiesel is produced by transesterification of vegetable and animal oils and fats with monoalcohols and is chemically a fatty acid methyl ester. The properties of biodiesel are crudely given by the chain length of the composing molecules, their saturation degree, the concentration of fatty acid methyl esters, and finally by the structure of the esters depending on the feedstock. Another approach is to use biowaste for the production of combustibles, examples are pyrolysis oils.

\section{4 | Edible oils}

Vegetable and animal oils and fats used as edibles are often extracted from plant seeds or pulp (olive oil) and animal tissues. Oils are roughly defined as being liquid at room temperature. Again crudely speaking, animal "oils," on the other hand, are mainly solid at room temperature and therefore are called fats. An exception are fish oils. Animal 
oils and fats are mainly extracted from animal tissues; alternatively, they can also be obtained from milk. Dairy products are representative for this class.

Edible oils mainly consist of triglycerides, the ester of glycerol with three fatty acids. Di- and mono-glycerides are also known but not as common and widespread as triglycerides. The chain length of fatty acids varies; food oils usually consist of a number of $-\mathrm{CH}_{\mathrm{x}}-$ groups in the range of $16-26$ with a $-\mathrm{CH}_{3}$ and a $-\mathrm{COOH}$ end group. Prominent examples are oleic acid, palmitic acid, or linoleic acid, to name a few. Not only the molecular weight, but also the chemical bonds, that is, the hybridization of the $\mathrm{C}$-atoms as $\mathrm{sp}^{3}$ and $\mathrm{sp}^{2}$, vary and are used for classification. Saturated, unsaturated, and polyunsaturated fatty acids are differentiated. Among polyunsaturated fatty acids, the essential oils are of interest for industry. Regarding nomenclature, fatty acids are referred to as omega- 3 or omega- 6 fatty acids depending on the position of the first double bond from the $-\mathrm{CH}_{3}$ end group.

The average global production of vegetable oils from oil seeds amounted to $174.1 \mathrm{Mt}$ per year between 2013 and 2015, with palm oil, soy oil, rapeseed, and sunflower oil accounting for the majority (87\%). A total of $141.6 \mathrm{Mt}$ of these oils were used in food, and 22.4 Mt were used as biodiesel. At an average price of $782.2 \mathrm{USD} / \mathrm{t}$, this results in an enormous financial volume in the food market. ${ }^{[130]}$

Especially in the case of high-quality polyunsaturated fatty acids, such as fish oils or olive oil, false declarations of origin or of adulteration with other, cheaper oils occur with increasing frequency. Rapid and reliable analytical methods are urgently needed to protect both producers and consumers.

Edible oils and fats are often dispersed in foods. Not only chemical composition but also texture and mouth feeling are of major interest, which are often related to the form and length scales of dispersion. Consequently, measurement techniques are searched for, which are capable to measure these characterizing quantities reliably.

\section{3 | LF-NMR TECHNIQUES IN RESEARCH AND QC}

The development of new analytics in QC primarily plays an important role, if established methods do not meet the actual demands, for example, robustness, sensitivity, specificity, and reliability. Over time in the development of LF-NMR, applications in QC have become more and more important. LF-NMR devices are usually based on permanent magnets and therefore do not require cooling by cryogenic liquids. Advantages of LF-NMR compared with high-field NMR are the lower costs in investigation and maintenance as well as robustness. Disadvantages of LF-NMR are the lower magnetic field, sensitivity, and lower magnetic field homogeneity, whereas the dominance of $J$ coupling increases compared with chemical shift dispersion at lower magnetic fields.

\section{1 | Time-domain NMR: Relaxation and diffusion}

Typical time-domain (TD) NMR devices record timedomain ${ }^{1} \mathrm{H}$ NMR data often without chemical shift resolution due to the magnet's inhomogeneity. The first QC TD-NMR applications were based on the exploration of the molecular dynamics by means of relaxation and diffusion. ${ }^{[62,131-135]}$ Equally important as data generation was and is data processing and interpretation. To obtain simple and meaningful QC parameters, data reduction is indispensable. Therefore, only those parts of the free induction decay (FID), which are meaningful for the application, were acquired and quantified. A prominent example is the solid fat content (SFC) determination to be discussed later. Nowadays, in TD-NMR measurements of transverse relaxation, often the Carr-PurcellMeiboom-Gill (CPMG) pulse sequence ${ }^{[95]}$ is used, in which thousands of echoes are acquired to reliably measure the magnetization decay. Relaxation data of "simple substances" can be described by a monoexponential function, which is theoretically based for example on the Bloch equations. ${ }^{[136]}$ From the physical point of view, this approach is limited in describing multicomponent mixtures in a meaningful way. Inverse Laplace transformation (ILT) algorithms were therefore developed resulting in relaxation time distributions. ${ }^{[137,138]}$ One major disadvantage of this approach is its numerical instability for signals with small signal-to-noise ratios, which are almost always present in TD-NMR relaxation data. ${ }^{[139]} \mathrm{A}$ regularization parameter is often user-specific and therefore more or less subjective. Especially in the case of automated data processing, the use of the ILT is difficult with respect to repeatability and reliability. Comparability of data and physicochemical interpretation are sometimes limited as well. Nevertheless, there is significant development going on, also regarding the correlation analysis of relaxation data among themselves and relaxation with diffusion data, for example. ${ }^{[140,141]}$ Another promising approach to relaxation data of complex mixtures is the gamma distribution model ${ }^{[96]}$ initially presented for NMR diffusion data by Röding et al. ${ }^{[142]}$ Within this model, magnetization decays either due to relaxation or due to molecular diffusion in gradients are described by distributions of relaxation rates or diffusion coefficients. In case of monomodal distributions, two quality parameters result: the mean relaxation rate or diffusion 
coefficient and the corresponding distribution width. Besides LF-NMR relaxation, NMR diffusion measurements are historically a major analytical tool in QC, for example, for droplet size determination in emulsions. ${ }^{[143-147]}$ Often used pulse sequences are the pulsed field gradient spin echo or the pulsed field gradient stimulated echo sequence.

As longitudinal relaxation depends on the magnetic field, ${ }^{[148-150]}$ longitudinal relaxation was often investigated as a function of the magnetic field. Field cycling NMR relaxometers allow the measurement of the longitudinal relaxation time $T_{1}$ as a function of the magnetic field within one apparatus at LFs. Typical ${ }^{1} \mathrm{H}$ Larmor frequencies of the magnetic fields in which relaxation takes place range from a few $\mathrm{kHz}$ up to $42 \mathrm{MHz} \cdot{ }^{[151]}$ Field cycling NMR is often applied to answer questions concerning contrast agents, that is, their paramagnetic relaxation, ${ }^{[152]}$ and liquids within pores. ${ }^{[153]}$

\section{2 | Spectroscopy in LF-NMR}

Apart from relaxation and diffusion, NMR spectroscopy provides detailed informations about the chemical composition of samples. Over the years, attempts were made to design permanent magnets for sufficient homogeneity to allow chemical shift resolution..$^{[2,8,9,154,155]}$ Main applications are nowadays reaction monitoring and education, whereas research is going on to improve the applicability and to enlarge the diversity of NMR further, also in form of fast two-dimensional (2D) experiments. ${ }^{[156]}$

\section{4 | LF-NMR IN OIL PRODUCTION, FORMULATION AND USE}

As the number of applications of LF-NMR is rather large, this section of the review is structured along the main processing chain of oils. Starting from production and the applications of LF-NMR in this area, formulation processes and finally the changes of oils during use and abuse are addressed as they appear from the perspective of LF-NMR in research and QC. The differentiation between edible and technical oils is also retained in this section.

\section{1 | Production}

\subsection{1 | Crude oil}

The characterization of crude oil using methods of LFNMR already begins with rock core analysis in boreholes. Well logging properties of subsurface earth formations are measured in situ. The primary aim is to detect reservoirs in different porous layers of the earth filled with water, gas, and oil. Extreme conditions in these up to $10-\mathrm{km}$ deep boreholes require robust equipment that enables reliable analysis even at high temperatures and pressures in chemically and structurally drastically varying environments. The findings are essential for the identification of new industrially usable wells for crude oil production. NMR well logging is almost as old as NMR itself, the first investigations date back to the 1950s. In the beginning, well logging was still carried out using the earth's magnetic field. Meanwhile, NMR proved to be much more powerful and was successfully applied already in 1983. Further technical developments led to the fact that nowadays well logging can be carried out at the same time as drilling. $B_{0}$ and $B_{1}$ fields are generated within the NMR device and characterize the environment ex situ. The fields are relatively weak and strongly inhomogeneous; therefore, no chemical shift information is available. The characterization is based on the measurement of relaxation and diffusion, whereby CPMG in particular proved to be effective in the strongly inhomogeneous fields. ${ }^{[15-39]}$

LF-NMR meanwhile is an important tool for the characterization of crude oil. ${ }^{[40]}$ Alternative and established analytical methods are most often ex situ and need large amounts of solvents. Typical questions concern the identification and classification of crude oils, that is, the chemical characterization and quantification of the complex mixtures of different oil fractions or reservoirs. ${ }^{[41]}$ Measurement of viscosity ${ }^{[32,42]}$ and determination of droplet size distributions of emulsions ${ }^{[43]}$ are also issues in this field. Crude oils are complex organic mixtures and contain several thousands of components. ${ }^{[44]}$

In oil refineries, online NMR, also in combination with generalized predictive control, is used to monitor the oil composition and to manage crude transitions in refinery logistics. ${ }^{[157]}$ Although one-dimensional (1D) ${ }^{1} \mathrm{H}$ NMR spectroscopy is used to obtain information about the chemical composition, relaxation measurements provide information about molecular dynamics. The additional use of multivariate data analysis such as principal component analysis (PCA) and partial least squares regression (also named projection on latent structures regression, PLSR) allows the correlation between gravity or viscosity with NMR parameters. ${ }^{[40-42,158,159]}$ Viscosity of heavy crude oils also containing asphaltenes was determined by transverse and longitudinal relaxation. ${ }^{[160]}$

\subsection{2 | Edible oils: Seed and raw material analysis}

The quality of many natural products and raw materials is subjected to regional and seasonal fluctuations. In 
order to ensure a sufficiently good product quality, an exact analysis and knowledge of the raw natural material is necessary before further processing-apart from the fact that quality determines the price to be payed to farmers and producers. An important application field of LF-NMR is found in QC of seeds and their residues, which are used both, in food industry and in industrial processing to biodiesel and bioethanol. Important indicators for the seed quality are the concentrations of oil, moisture, ash, and proteins as well as the fatty acid profile.

The potential of NMR to determine the oil content of seeds was already described some decades ago and is still applied ${ }^{[46-51]}$ and well established in a common norm. ${ }^{[161]}$ The oil content of the predried, intact seeds of different plants was determined. Due to the significantly slower transverse relaxation rates, ${ }^{1} \mathrm{H}$ NMR signals of oil could be distinguished from those of bound water, carbohydrates, and proteins. Because free water also shows small relaxation rates, which distinctly depend on the chemical environment, this technique is limited for high water contents. Quantification is therefore difficult; nevertheless, attempts were made early ${ }^{[47-49]}$ : Tiwari et al. ${ }^{[47]}$ investigated the influence of water content, shape, and positioning of seeds in the NMR tube with respect to reproducibility and accuracy of the oil content determination. The study was carried out on peanut seeds and Brassica and was optimized with regard to the measuring time. The FID shows different rates for the different components in the seeds. For example, the signal of the ${ }^{1} \mathrm{H}$ nuclei of bound water, proteins, and carbohydrates decays much faster than that of the oil due to the shorter $T_{2}$ relaxation time. Conclusions were drawn about the oil concentration analyzing the form of the signal decay. Further investigations were successfully carried out on olive husk, ${ }^{[162]}$ sunflower seeds, soy beans, and mustard seeds. ${ }^{[48]}$

Due to advances in LF equipment and experiments, other methods for determining the oil content could be implemented: A spin echo experiment allows the simultaneous determination of moisture and oil concentrations. ${ }^{[49,163,164]}$ The difference of the signal amplitudes of the FID $S_{1} 50 \mu \mathrm{s}$ after the $90^{\circ}$ preparation pulse and of the echo $S_{2}$ after $7 \mathrm{~ms}$ is assigned to moisture and oil content via a calibration. In order to ensure that free water with $T_{2}$ relaxation time larger or in the range of the oils does not significantly influence the measurement, the water concentration must be below 15\%. This method requires a minimum of sample preparation and reliably determines oil and moisture contents within some tens of seconds. Prerequisite is a previous and reliable calibration by series of samples of known oil concentration. This method for simultaneous determination of oil and moisture contents of seeds is also described in industry standards. ${ }^{[165-167]}$ Meanwhile, the oil content of numerous seeds (canola, corn, sunflower, cotton, flax, poppy, soya, mustard, hemp,$^{[164]}$ and tobacco seeds ${ }^{[51]}$ ) and other foods (olives, ${ }^{[168]}$ nuts, chocolate, milk powder, bakery powders, cheese, and sausages ${ }^{[135]}$ ) could be determined successfully.

In a comparison between the acquisition of FIDs, spin echoes, and CPMG echo trains, it was shown that the CPMG sequence was most suitable for determining the oil concentration due to a less pronounced dependence on moisture concentration and on positioning in the tube, that is, sample and magnetic field inhomogeneity. ${ }^{[163]}$ The already more or less dry seeds show low water signals with distinct relaxation properties, that is, a predrying of the seeds is usually not necessary. Thus, a completely nondestructive analysis is available in form of this LF-NMR method.

For accurate results, in recent years, the experimental results have increasingly been correlated involving multivariate, that is, chemometric data analyses. This approach is valuable especially for wet natural products and foods. Pedersen et al. ${ }^{[169]}$ compared the conventional approach of data processing, that is, a monoexponential fit to an FID, with chemometric results using a JackKnife validation. The oil content of rapeseed and mustard seed could be determined without predrying of the seeds.

From oil concentrations of different seeds, conclusions can also be drawn about other ingredients. Therefore, a correlation between oil concentration and protein concentration of soybeans was established. ${ }^{[170]}$ In addition, Horn et al. ${ }^{[171]}$ showed a possibility for the simultaneous determination of oil and protein concentrations of cotton. A different approach is to exploit both, longitudinal and transverse relaxation simultaneously, which was the basis for the measurement of body mass composition of small animals by LF-NMR. ${ }^{[172,173]}$ Modifying the pulse sequence into a saturation-based sequence lowered the measurement time and led to a LF-NMR application capable to determine water, oil, and hard materials within one experiment. ${ }^{[98,174]}$ Quantification was achieved by regarding the NMR signal as a fingerprint, which can be correlated with results of other analytical tools. In these cases, wet chemical tools were used, and a chemometric model, here PLSR, was calculated to establish a quantitative correlation.

In order to achieve the highest possible throughput for a $100 \%$ control of natural products, fast NMR measurements are desirable. Colnago et al. ${ }^{[175]}$ proposed a NMR method based on steady-state free precession of nuclear magnetization, known as continuous wave free precession. Thus, the oil and fat content of agricultural products 
(palm fruit, castor bean, and watermelon seed) could be accurately determined. Furthermore, a correlation of the concentration of sunflower oil in carbon tetrachloride with the amplitude of ${ }^{1} \mathrm{H}$ continuous wave free precession signal was demonstrated. ${ }^{[176]}$

LF-NMR is an efficient analysis tool in screening processes; of course, its applicability strongly depends on throughput and other prerequisites of the process. A throughput of 1,400 samples per day was realized in the oil content determination of oats. ${ }^{[177]}$ A sequence with three key components was used: the acquisition of a FID, a spin echo, and a combined $T_{1} / T_{2}$ relaxation. The correlation with chemometric data processing allowed screening with this high sample throughput.

Quality and composition of the raw natural materials are of decisive importance not only in food but also in biodiesel production. Seeds with fatty acid profiles that do not contain (poly)unsaturated fatty acids but saturated fatty acids are required, preferentially with high yields. Prestes et al. ${ }^{[45]}$ used a CPMG pulse sequence to detect the transverse magnetization decay, which is of course multiexponential as diverse substances contribute. Again chemometric data processes revealed a clustering of the decays, which allowed a classification of diverse seeds. Thus, the fatty acid profile of palm oil and linseed could be qualified and quantified. A complete picture of seed quality was obtained and related to classic classification schemes such as cetane number, iodine value, and kinematic viscosity by clustering the NMR results.

Fatty acid profiles of living fish currently are of high nutritional interest. Such a profile depends on breeding conditions and feeding, which have to be optimized in the fish farms. The fat concentration of Atlantic salmon was determined in vivo by single-sided NMR using CPMG. ${ }^{[52]}$ Modeling the signal decay by a biexponential, two essential values of $T_{2 \text {,eff }}$ were assigned to water and fat. A calibration with results from chemical extraction after slaughtering allowed an accurate quantification of both components. The measurements took $20 \mathrm{~s}$ per fish.

\section{2 | LF-NMR in formulation of oils}

\subsection{1 | ${ }^{1} \mathbf{H}$ content of hydrocarbons}

The quality of oils depends on the saturation degree and the molecular weight, which correspond to the number of ${ }^{1} \mathrm{H}$ in a given volume or mass. As the NMR signal intensity is proportional to the number of contributing spins, the number of ${ }^{1} \mathrm{H}$ in oils can be quantified by measuring the FID after a calibration with known substances of similar chemical composition such as alkanes. This application of TD-NMR was standardized and is commonly applied in industrial processes. ${ }^{[53]}$

Depending on the application, lubricants considerably differ in their chemical composition. Apart from the choice of a suitable base oil, this mainly concerns the additives. By the specific use of additives during oil formulation, a large number of parameters are characteristic for oil quality and can be adjusted. These include, for example, viscosity index, viscosity, total acid number, and total base number. The limits of application and the suitability of the lubricants can currently be estimated less on the basis of well-founded scientific knowledge but more on the basis of profound experience. LF-NMR can also contribute to a better understanding and characterization of lubricants. A correlation between viscosity and transverse relaxation was found for noncontaminated oils. In the near future, LF-NMR spectroscopy could also be used to make the formulation and characterization of lubricants more efficient and reliable. The high information content about chemical structure and composition facilitates an accurate additive formulation and thus an exact adjustment of the quality parameters of the oils, maybe also with respect to a better ecological use of these valuable resources.

\subsection{2 | QC of biodiesel oils}

Biodiesel produced from vegetable oils or animal fats has become an alternative to fossil fuels. ${ }^{[10]}$ Different feed stocks are currently used such as food grade soybean, corn, rapeseed, and sunflower oils. These oils are often subjected to a transesterification. Methanol is typically used as the short chain alcohol and $\mathrm{NaOH}$ or $\mathrm{KOH}$ as the base catalyst. Low-field ${ }^{1} \mathrm{H}$ NMR spectroscopy was shown to monitor the transesterification reaction. ${ }^{[10,54,55]}$

Two prominent peaks characterize the transesterification: the peak of the glyceridic ${ }^{1} \mathrm{H}$ has a chemical shift of $4.2 \mathrm{ppm}$, only being present in the oil, whereas the signal of the methyl ester ${ }^{1} \mathrm{H}$ at $3.66 \mathrm{ppm}$ is attributed to biodiesel.

Not only chemical composition but also molecular dynamics and translational diffusion are quality characteristics of biodiesel. Fatty acid methyl esters, being derivated from fatty acids, are the basis of biodiesel. ${ }^{[56]}$ The molecular structure of the fatty acid methyl esters significantly affects the physicochemical properties of biodiesel, which can be determined by LF-NMR. ${ }^{[56,57]}$ It was shown that measuring the transverse magnetization decay and analyzing the data by ILT lead to insight into the properties. Several peaks in the relaxation distribution sign different proportions of different molecular mobility in biodiesel. 
Also, fossil diesel oils are of considerable importance for both road and sea transport and are obtained by refining crude oils. To make even more money in this big market, adulterations occur. Kerosene was and might be added to diesel oils as it has a good miscibility and is much cheaper but also leads to irreparable damage in, for example, cars. As a consequence of this adulteration, difficulties result in starting the engine, the amount of emission and exhaust gasses increase. ${ }^{[58]}$ To detect this type of contamination, TD-NMR transverse relaxation represents a good tool to measure the concentration of kerosene in diesel oils. ${ }^{[58]}$ Additionally, the determination of several commonly used quality characteristics such as refractive index, viscosity, density, and total acid number is possible by transverse relaxation. ${ }^{[159]}$

Lignocellulose-based biomass is often processed by pyrolysis apart from gasification and fractionation. The composition of pyrolysis oils can be measured not only by conventional $\mathrm{NMR}^{[59,60]}$ but also by $\mathrm{LF}{ }^{1} \mathrm{H}$ NMR spectroscopy revealing the major chemical components. Water content was measured, which is of interest for subsequent process steps like combustion. ${ }^{[61]}$

\subsection{3 | Edible oils and fats: SFC}

SFC is a key quality parameter in many edible oils and fats in production but also in product development. Other methods, such as dilatometry, have drawbacks, for example, lower accuracy and large measurement times. Various early publications have shown that wide line or TD-NMR is suitable for determining SFC ${ }^{[63,64]}$ In 1973 , van Putte et al. $^{[62]}$ showed how to determine the solid/liquid ratio in semicrystalline fats. The ${ }^{1} \mathrm{H}$ magnetization decay in an FID after a $90^{\circ}$ radio frequency pulse can be divided into the rapid decay of the ${ }^{1} \mathrm{H}$ magnetization of the solid fat and the slower decay of the liquid fat. The ratio of both is temperature dependent, of course. In protracted studies and ring tests, the signal intensity after $70 \mu$ s was defined to reflect the liquid part. The amount of solid fat can either be determined indirectly by melting the sample. Alternatively, the direct method $^{[134]}$ was developed, that is, the signal intensity after $11 \mu \mathrm{s}$ is quantified, whereby a correction factor for the dead time of the radiofrequency circuit is often taken into account. A further study showed the possibility of a fully automated SFC determination within a few seconds. ${ }^{[65]}$ Various products were studied such as sunflower, rapeseed, palm, coconut oil, or also hydrogenated fish oil, the results are in line with those of dilatometry and finally resulted in standardized applications of TD-NMR: The determination of SFC by TD-NMR was first recorded in an International Union of Pure and
Applied Chemistry method in 1982. Meanwhile, SFC determination in bulk fats and oils is established in several standards. ${ }^{[66-69,134]}$

SFC was and is measured by TD-NMR on margarine fats, ${ }^{[70]}$ on hard confectionery butter fats, ${ }^{[71]}$ and tempering fats (cocoa butter and their equivalents). ${ }^{[131]}$ The quality of these tempering fats depends to a large extent on crystal size and morphology. The temperaturedependent formation can be traced by TD-NMR.

The often used direct method for SFC determination is relatively limited and does not use the complete information available in TD-NMR. Additionally, it requires correction factors, which need to be determined. To extract the complete information and to circumvent the restrictions, van Duynhoven et al. ${ }^{[72]}$ proposed curve fitting for modeling the NMR signal. ${ }^{[73]}$ In a combined FID-CPMG experiment, good correlation was achieved in comparison with the established direct and indirect method with regard to accuracy and precision. ${ }^{[74}$ Transverse relaxation decay deconvolution leads to SFC among other parameters. Another example for the application of transverse relaxation decay deconvolution is the measurement of SFC of the fat-oil phase in oil-inwater $(\mathrm{O} / \mathrm{W})$ emulsions. ${ }^{[75]}$ The fact that the crystals morphology is reflected in the shape of the FID opens up new possibilities of characterization of crystalline macromolecular materials, for example, polymers.

Temperature-dependent TD-NMR measurements allow studying the SFC content as a function of cooling rate. ${ }^{[76]}$ This allows the detection of parameters, which were previously inaccessible and which are important in time and temperature-dependent crystallization processes. Crystallization is known to depend on the shear exerted on the material. The crystallization of canola stearin in canola oil in a Couette cell at different shear rates was investigated. ${ }^{[77]}$ The experimental setup provided reproducible and comparable SFC results, which were compared with static measurements. The approach is promising for the detailed investigation of the effects of shear flow on SFC of nanostructured or macromolecular multicomponent systems.

Emulsions represent an important field in food science and industry, whereas SFC is known to have a major influence on product quality. A direct SFC determination in emulsions is complicated due to the difficult distinction of the signals from dispersed and quasi-continuous phases. The measurements are additionally affected by transverse water relaxation, which itself depends on the food network. Linke et al. ${ }^{[78]}$ presented a way to determine SFC even in emulsions with a high water content. By an additional magnetization inversion, followed by an appropriate recovery delay, the pulse sequence was changed so that the SFC for an $\mathrm{O} / \mathrm{W}$ emulsion based on 
a medium chain triglyceride and an $\mathrm{O} / \mathrm{W}$ emulsion made of tristearin could be determined successfully. Further work concerns the monitoring of crystallization as a function of time and temperature.

\subsection{4 | Droplet size distribution by LF- NMR}

Essentially, two NMR parameters are known to be sensitive to geometrical hindrance, namely, relaxation and diffusion. Both methods can be applied to disperse systems of food and technical oils, mainly emulsions. Although relaxation is often explored in porous solids ( $T_{1}$ in field cycling or $T_{2}$ at larger magnetic fields), for example, in the field of crude oil exploration, which exhibit large surface relaxation, the diffusion-based approach is commonly applied in food emulsions.

Pulsed field gradient experiments, most often in form of dedicated pulsed field gradient stimulated echo experiments, record the magnetization decay as a function of gradient duration or better of gradient amplitude. Differentiation of oil and water phases is achieved by their specific relaxation and diffusion properties as most often, PFG-NMR in LF is realized without chemical shift dispersion. Modeling is commonly made along the description given by Murday and Cotts, ${ }^{[79]}$ combined with a logarithmic normal distribution. ${ }^{[80,81,145,146]}$ The distribution function, often in form of the monomodal log-normal distribution, is only a matter of numerical implementation. The distribution function can be adapted to the needs of the emulsion under investigation. ${ }^{[82]}$ Also, regularization approaches ${ }^{[83]}$ are known, which confirm the applicability of the log-normal distribution so far. All these studies and the application in industrial environments based upon the fact that the mean free path length of molecules inside a droplet is restricted due to the disperse nature of the material. The method is therefore limited on the length scale: In case the droplets are too large, the experience of the restriction is too small to be quantified in terms of droplet size distribution. In case the droplets are too small, the dynamics of the droplets as a whole determines the overall and ensemble averaged diffusion. This case was found to be describable by using the classic Stokes-Einstein relation combined with a distribution function. ${ }^{[84]}$ Droplet sizes below $1 \mu \mathrm{m}$ were successfully determined and found to be comparable with the results from dynamic light scattering. ${ }^{[85]}$ Multiple emulsions were also measured. Quantification and interpretation of data are highly demanding for this type of emulsions. ${ }^{[86-89,143]}$

Another completely nondestructive approach is offered by single-sided NMR for the determination of oil or fat concentrations in food products by LF-NMR, which can be designed much more compact than other benchtop NMR instruments. Moreover, geometrical restrictions are relaxed concerning the shape of the sample to be investigated. For example, "through package" measurements are possible. ${ }^{[90,91]} \mathrm{In}^{[92]}$ the application of NMR mobile universal surface explorer was summarized for material analysis. The strongly inhomogeneous magnetic field in single-sided NMR results in a permanent but spatially dependent magnetic field gradient. This causes the transverse magnetization decay being influenced not only by transverse relaxation but also by translational diffusion. An effective relaxation rate $T_{2 \text {,eff }}$ is measured, and the two main influencing factors can be separated at least qualitatively by measuring at different effective diffusion, that is, echo times. The principle was also applied to study food emulsions. ${ }^{[93]}$ The NMR answer of the sample can be designed using multiecho pulse sequences. Transverse relaxation can also be combined with longitudinal magnetization weighting; quantitative measurements were successfully performed using this approach.

\section{3 | LF-NMR on oils in use}

\subsection{1 | Engine oils}

Oils often undergo irreversible aging processes during usage. From the ecological, economical as well as from the machines point of view, optimal oil change intervals are highly desirable. Commonly applied analytical methods are GC-MS, FTIR, viscosity measurements, and ICP-OES ${ }^{[178-180]}$ — among others.

Due to the widely spread use of engine oils, diverse aging mechanisms and contaminants are postulated and often discussed controversially:

- thermal oxidative aging probably catalyzed by metals present in the machines (e.g., copper), which changes the chemical composition of oils, especially of additives;

- acids, which are caused by thermal oxidative stress and accelerate degradation of additives;

- evaporation of volatile substances changing chemical composition, diffusion, and relaxation of the oil;

- cracking with the corresponding reduction of the oil's molecular weight distribution, that is, changes in relaxation and diffusion;

- resinifying accompanied by an increase of molecular weight, that is, changes in relaxation and diffusion;

- penetration and deposition of foreign substances such as water or fuels especially in the case of motor oils changing physical and chemical properties of the oils; 
- particulate abrasion, that is, changes in relaxation and diffusion.

In the following, examples will be discussed, which show the applicability of NMR to detect the consequences of these aging effects.

\subsection{2 | Particulate contamination}

During usage, gear oils often become contaminated by particles due to abrasion in gears or bearings (Figure 2). Depending on the nature of the often metallic machine parts, the abraded particles are potentially magnetic, that is, ferromagnetic, paramagnetic, or superparamagnetic depending on the particles material and size. Small particles and more or less in oil dissolved ions will be discussed below.

In the sagittal MR image of the fresh oil sample (Figure 2, middle), no particles are visible, whereas the contaminated sample shows-already in the visual impression (Figure 2, left) - a significant texture in the MR image. Magnetic susceptibility differs between particles and oil which damage the magnetic field homogeneity-also drastically influencing of course the line width in NMR spectroscopy. Apart from these obvious contaminations, which are often removed by filtration, nanoparticles may remain, which could be magnetic or diamagnetic. If so, they are no longer detectable via exploration of magnetic field homogeneity, which is valid also for small nanoparticles. However, NMR offers a different tool: Geometric hindrance of oil diffusion can be detected by PFG-NMR, specifically, under variation of the diffusion time $\Delta$. In the case of free diffusion, the diffusion coefficient $D$, that is, the magnetization decay as a function of gradient amplitude or duration, is expected to be independent of $\Delta$. The magnetization decays measured on the contaminated gear oil instead showed an implicit dependence on $\Delta$ (Figure 2), whereas $b$ is the product of the magnetogyric ratio $\gamma$, the gradient pulse duration $\delta$, its amplitude $g$, and the reduced diffusion time $(\Delta-\delta / 3): b=(\gamma g \delta)^{2}(\Delta-\delta / 3)$. With increasing $\Delta$, the slope of the magnetization decay changes indicating geometrically hindered diffusion.

Please also note that the magnetization decays do not form a straight line in the representation (Figure 1, right) but show a curvature. This deviation from the classic theoretical expectation ${ }^{[94]}$ is due to the mixture of various substances and the high concentrations of larger molecules with inherent degrees of freedom regarding conformation and entanglements. Currently, applied data processing approaches are therefore either the numerical approach via ILT or the modeling via an analytic distribution function.

Summarizing, particulate contamination in oils can be detected by NMR via susceptibility differences (line width or magnetic resonance imaging) or geometrical hindrance (PFG-NMR). Particles in the small nanometer range and paramagnetic ions cause additionally measurable paramagnetic relaxation enhancement (PRE). ${ }^{[181]}$

\subsection{3 | Physicochemical implications of aging}

Due to the chemical composition of technical oils and as the environmental conditions cover large ranges, a generally valid rule of thumb for changes in relaxation and diffusion properties could not be established so far. Instead, the potential of LF-NMR is discussed on the example of an engine oil that was systematically stressed in an engine test rig. Transverse relaxation and diffusion were measured. Analyzing the data by the $\Gamma$-distribution model lead to mean values and distribution widths of relaxation and diffusion coefficients. With increasing runtime the mean transverse relaxation rate $R_{2}$ and the distribution's width increased, whereas the mean diffusion coefficient $D_{\text {mean }}$ decreased. ${ }^{[96]}$

Longitudinal relaxation of engine oils as measured by fast field cycling FFC-NMR was shown to be also sensitive to aging: The relaxation dispersion $R_{1}\left(\omega_{0}\right)=1 / T_{1}\left(\omega_{0}\right)$ itself is sensitive to the oil formulation. With increasing runtime, $R_{1}$ increased for two oils. ${ }^{[95]}$ The largest differences were observed at Larmor frequencies $\omega_{0}=2 \pi \nu_{0}$ in the range of several kilohertz, indicating that molecular fluctuations, which are influenced by aging, are predominantly in this frequency range of several kilohertz. These findings are in agreement with classic NMR relaxation studies where the larger sensitivity towards aging processes was found in transverse relaxation, which also reflects molecular dynamics at low frequencies in the kilohertz range.

Transverse and longitudinal ${ }^{1} \mathrm{H}$ relaxations of organic materials are often dominated by homonuclear dipolar couplings. However, PRE is not negligible in samples containing (super)paramagnetic substances. This fact is exploited in magnetic resonance imaging in form of contrast agents. As already mentioned, abrasion leads to particulate contamination of oils which are often not diamagnetic. In a first approach, PRE and homonuclear dipolar coupling contribute according to the concentration of magnetic impurities to the total relaxation rate. For a quantitative and reliable analysis of the data, not only the concentration of (super)paramagnetic impurities but also their relaxivities have to be considered, which are 

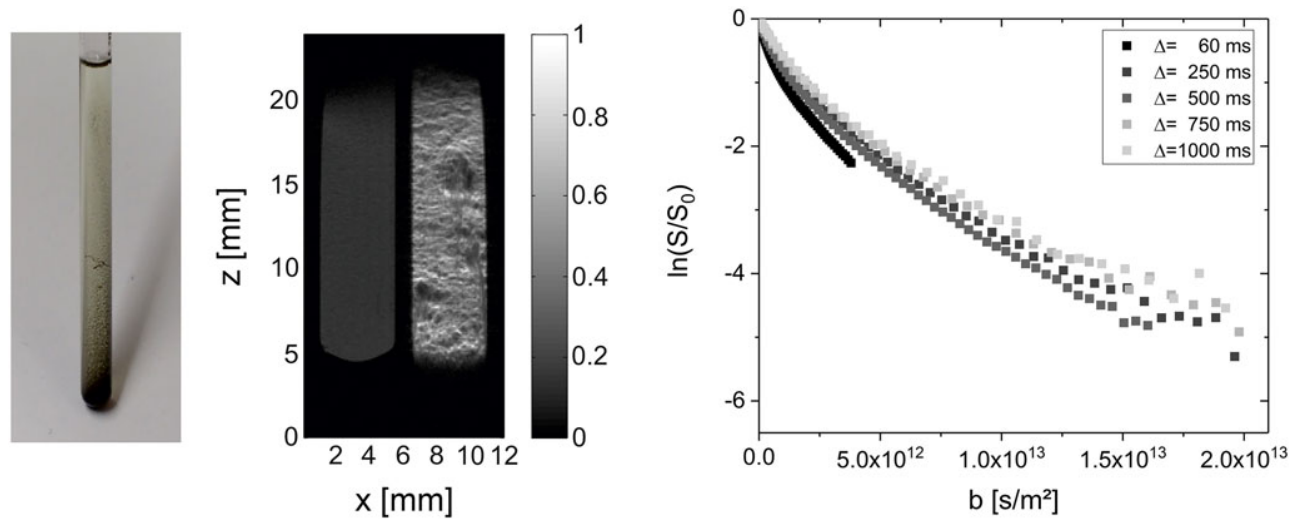

FIGURE 2 Left: Photo of a NMR tube with aged gear oil with particulate contamination, in the middle: magnetic resonance image of a NMR sample tube containing fresh gear oil $(x=1.5-5.5 \mathrm{~mm})$ and the gear oil with particular contamination $(x=7-11 \mathrm{~mm})$. Right: PFGNMR signal decays measured on the aged gear oil for diffusion times $\Delta \in[60,1,000] \mathrm{ms}$. (PFG: pulsed field gradient)

a function of shape and size of the particles. Practically, estimates can currently be made in the sense of worstcase scenarios.

\subsubsection{Changes in chemical composition}

Chemical changes in oils in the course of aging were detected using high-field spectroscopy. ${ }^{[182-185]}$ Diverse 1D and 2D experiments (single pulse ${ }^{1} \mathrm{H},{ }^{15} \mathrm{~N},{ }^{13} \mathrm{C}$ and ${ }^{31} \mathrm{P},{ }^{1} \mathrm{H}-{ }^{1} \mathrm{H}$ COSY, ${ }^{1} \mathrm{H}^{13}{ }^{13} \mathrm{C}$ HSQC) provided a comprehensive view of the investigated oils. In particular, the degradation of additives and the increasing concentration of aging products can have a lasting adverse effect on the oil quality, which could be detected by low-field $1 \mathrm{D}{ }^{1} \mathrm{H}$ NMR spectroscopy (Figure 3).

The comparison of ${ }^{1} \mathrm{H}$ spectra of a fresh engine oil at 80 and $400 \mathrm{MHz}$ shows good agreement (Figure 4) despite of the lower signal-to-noise $(S / N)$ ratio and the more pronounced peak overlaps due to a wider spread of $J$ couplings (on the ppm scale, not in $\mathrm{Hz}$ ). The largest differences result from the dominant lines of $-\mathrm{CH}_{2}-$ and $-\mathrm{CH}_{3}$ groups at about 1.3 and $0.9 \mathrm{ppm}$, whose line feet reach up to $5 \mathrm{ppm}$. The range of higher chemical shifts $(>2 \mathrm{ppm})$ is of particular interest regarding the additives. Chemical reactions of these oil components serve as an indication for aging, mainly for thermal oxidative aging. Using prior knowledge from high-field spectroscopy, spectra can be quantified by line fitting. In addition, a partial suppression of the base oil signals, for example, by appropriate radio frequency pulses, potentially could facilitate the interpretation.

The applicability of low-field NMR spectroscopy for QC of engine oils is demonstrated on the already mentioned engine oils, that is, nine samples from an engine test rig were analyzed (Figure 5). The used oil was replaced by fresh oil in oil changes that took place after 665 and 1,255 hr. ${ }^{1} \mathrm{H}$ spectra are zoomed in, the chemical shift region is now limited to $2-13 \mathrm{ppm}$. The signature of aging was detected, whereby the spectrum of the fresh oil in particular differs from the others.

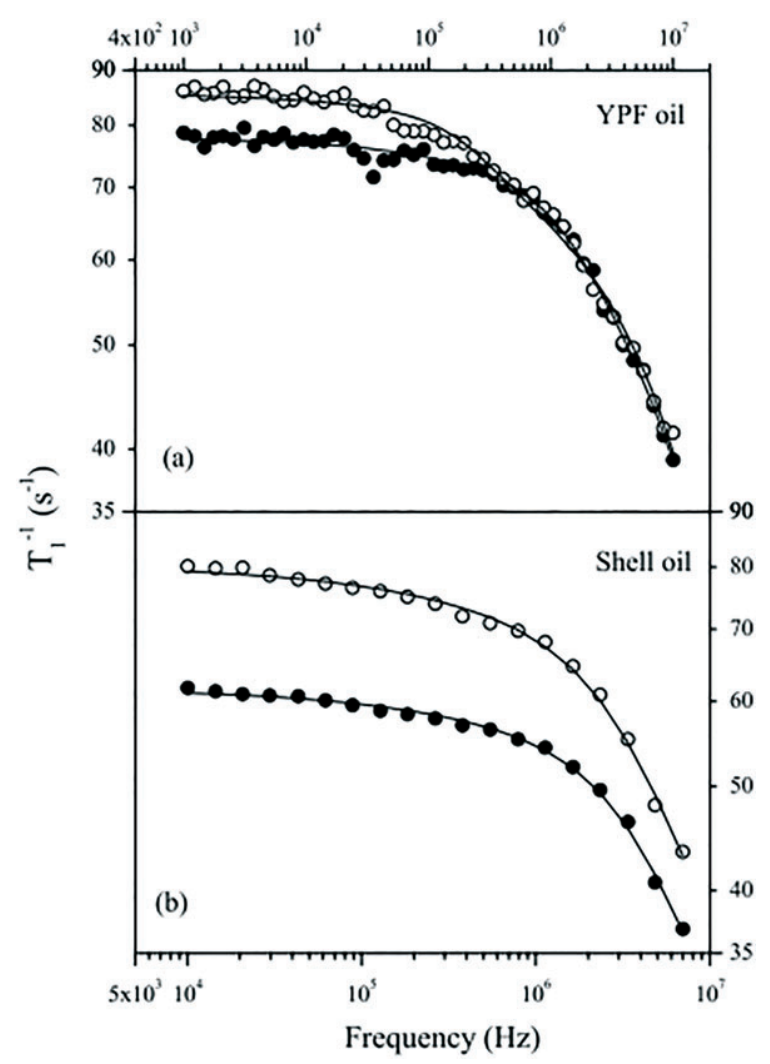

FIGURE 3 (a,b) $R_{1}$ dispersion for two engine oils. Filled points represent the measurements on fresh oils, the open circles that of degraded oils. ${ }^{[95]}$ The $T_{1}$ dispersion is pronounced in all cases. The sensitivity towards aging processes is the largest at low Larmor frequencies for both types of engine oils 


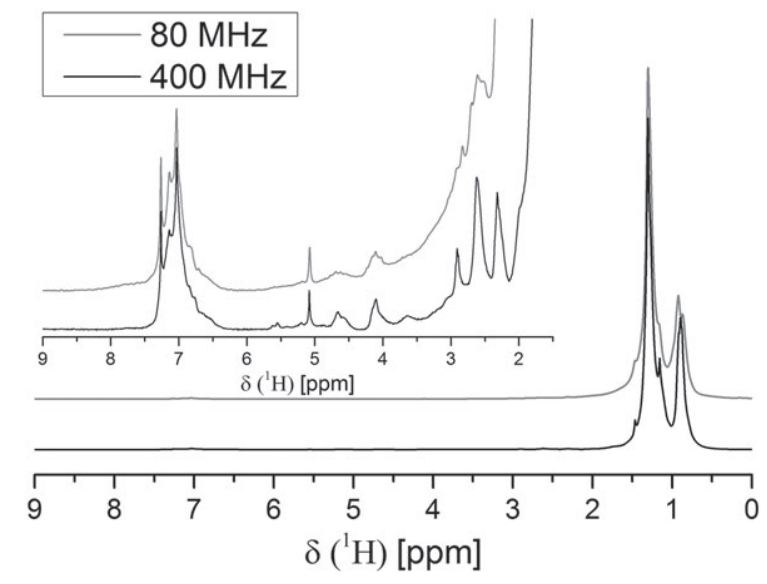

FIGURE $4 \quad{ }^{1} \mathrm{H}$ spectra of a fresh motor oil measured at $80 \mathrm{MHz}$ (gray) and $400 \mathrm{MHz}$ (black). The samples were diluted with deuterated chloroform $(99.8 \%, 1: 2)$ and accordingly referenced to residual $\mathrm{CHCl}_{3}$ at $7.26 \mathrm{ppm}$. The broader lines at $80 \mathrm{MHz}$ are mainly due to unresolved $J$ couplings, please compare with the residual $\mathrm{CHCl}_{3}$ signals at $7.26 \mathrm{ppm}$

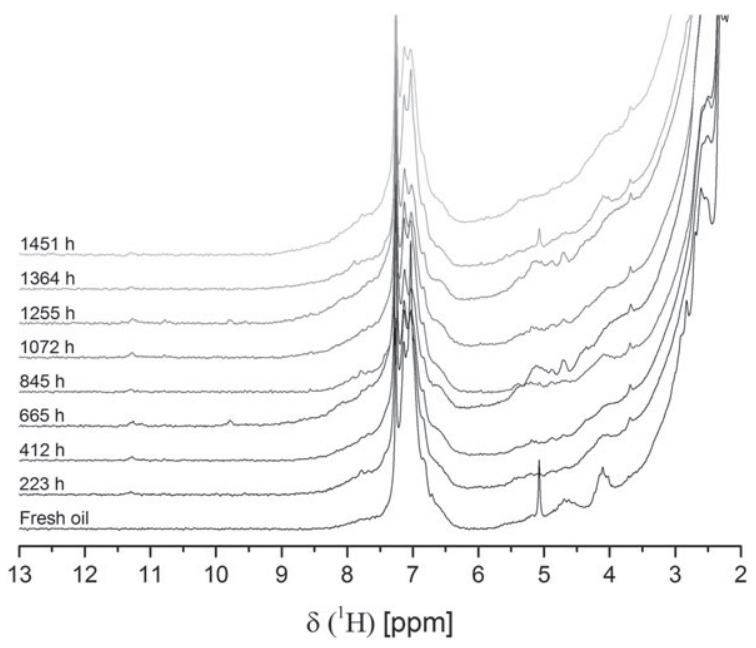

FIGURE $5{ }^{1} \mathrm{H}$ one-dimensional spectra of engine oils diluted with deuterated chloroform $(99.8 \%, 1: 2)$ at different runtimes, measured at $80 \mathrm{MHz}$. The oil of the engine test rig was changed after 665 and 1,255 hr, which is reflected in the spectra by a discontinuity. The spectra were referenced to chloroform at $7.26 \mathrm{ppm}$. Aging signatures are clearly visible over the whole chemical shift range $>2 \mathrm{ppm}$

The signal at $11.4 \mathrm{ppm}$ was exemplarily quantified by modeling with a pseudo-Voigt function and subsequent referencing to the integral of the $-\mathrm{CH}_{3}$ peak. The signal is assigned to a carboxyl group ( $\mathrm{RCOOH})$, which may be formed by oxidation of additives and therefore is a clear indication on the progressive aging of the oil. In the next step, all integrals were normalized to the maximum peak area of the carboxyl group at $t_{\text {run }}=665 \mathrm{hr}$ (Figure 6). A qualitative correlation between the concentration of the carboxyl compound and the running time of the oil was observed.

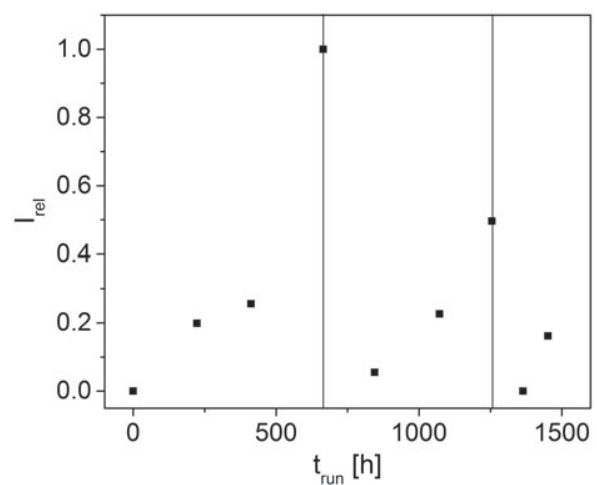

FIGURE 6 Relative integrals $I_{\text {rel }}$ of the carboxyl group at $11.4 \mathrm{ppm}$ as a function of runtime $t_{\text {run }}$ of the motor test rig, referenced on the $-\mathrm{CH}_{3}$ peak area and normalized to the peak area of the carboxyl group at $t_{\text {run }}=665 \mathrm{hr}$.. $I_{\text {rel }}$ reflects the oil changes after 665 and $1,255 \mathrm{hr}: I_{\text {rel }}$ is small after the oil change as it is for fresh oil

\subsection{5 | Biodiesel in use: Oxidation}

Aging of biodiesel was investigated by LF-NMR. This class of oils is known for aging by autoxidation. In Berman et al., ${ }^{[97]}$ this fact was studied by diverse analytical tools such as gas chromatography, Fourier transform infrared spectroscopy (FTIR), and by LF-NMR, here specifically by transverse relaxation. The transverse magnetization decays were analyzed via ILT. The resulting relaxation distributions reflect the composition and pronouncedly show the impact of autoxidation on molecular mobility, that is, of the spectral densities.

\subsection{6 | Edible oils in use/QC}

Oils and fats play an important role in various foods. The total lipid content and the type of crystal structure are decisive for mechanical properties and textures, taste, and storage stability. In many cases, LF-NMR enables a clear, cost effective, and fast analysis of products and proved to be well suited for QC.

The fat content of different emulsions (margarine and mayonnaise) can be determined using single-sided NMR. ${ }^{[98]}$ Two different LF-NMR methods, namely, a ratio method and a relaxation time method, were successfully applied.

The crystal structure of triacylglycerides (TAG) was investigated in several publications. ${ }^{[99-101]}$ The TAG morphology has a major influence on texture, sensory taste, and extended shelf life. Transverse and longitudinal relaxation and dipolar interactions reflected in the second moment $M_{2}$ allow to measure the polymorphism of TAG independently of chain length and sample temperature. Crystal growth was investigated in a cooling process. $T_{1}$ as a function of time could be related to Ostwald 
ripening. Conclusions were drawn about the size of the lipid crystals.

Conte et al. ${ }^{[102]}$ dealt with the supramolecular structure of triglycerides in extra virgin olive oil (EVOO). By modeling the longitudinal relaxation times with a biexponential fit, two components could be differentiated, the fast relaxing part was attributed to the polar head and the slow relaxing part to the apolar fatty acid tail. The TAGs seem to be arranged in inverse-micelle-like arrangements, with small amounts of polar EVOO molecules such as polyphenol, carotenoid, and chlorophyll providing stability by weak H-bonds. Adding acetic acid up to $20 \%$ increased the relaxation times, whereby the increase of the slower relaxing part was four times larger than that of the faster relaxing part. At even higher concentrations of acetic acid, phase separation was observed. The authors concluded that there was a rearrangement of the inverse-micelle-like structures towards a micelle-like organization. In consequence, EVOO is not disordered and amorphous liquids but is arranged in supramolecular aggregates. This raises completely new questions regarding their absorption path in human nutrition. In the course of a healthier diet, it is important to avoid excessive consumption of transfats. A possible alternative is high-stearic high-oleic sunflower oil, the crystallization behavior of which was investigated using LF-NMR relaxation, among other methods. ${ }^{[103]}$

Quantification of triglycerides using high-field NMR has been widespread for many years. Gerdova et al. ${ }^{[04]}$ were able to quantify various TAGs at $60 \mathrm{MHz}$ and confirm the results by a GC analysis. This can be used for the identification of adulteration food oils, for example, olive oil. In addition, it was shown that the TAG profile is very specific for different types of meat. A PCA considering spectral regions of olefinic, bis-allylic, and terminal $-\mathrm{CH}_{3}$ groups allowed meat samples from beef and horse to be clustered. ${ }^{[105]}$

LF-NMR was successfully used to determine lipid concentration in a large number of dairy products, for example, different products of milk powder such as infant formula ${ }^{[106]}$ and cottage cheese ${ }^{[107]}$ or packaged dairy products by unilateral $\mathrm{NMR}^{[108]}$ and to determine the solid/liquid ratio of anhydrous milk fat in hard and soft cheese. ${ }^{[109]}$ Conclusions on product quality or errors in maintaining the cold chain were reported from the relaxation behavior of crystalline fat phase in ice cream. ${ }^{[110]}$ Further studies describe the determination of the oil content in fried foods ${ }^{[111]}$ and the simultaneous determination of fat and water content in caramel. ${ }^{[174]}$

In $1 \mathrm{D}{ }^{1} \mathrm{H}$ spectra peak overlap limits an unambiguous assignment and thus the subsequent quantification and statistical analysis, especially at low magnetic fields. Standard 2D experiments are much more explicit in chemical assignment but have the disadvantage of large measurement times, sometimes several hours, and are therefore traditionally ruled out as a method in mass screening. By using a benchtop ultrafast 2D NMR method, it was shown that 2D measurements can be carried out in a short time period of less than 3 min..$^{[12]}$ Six different edible oils were clearly discriminated by a PCA of the data, also with respect to adulterations.

\subsection{7 | Adulteration of edible oils}

An important field in QC of food oils is the verification of authenticity. Adulteration is diverse, both false indications of origin and punching with other ingredients are known. Olive oil is often affected by adulteration. It is often mixed with cheaper vegetable oils (soybean, corn, sunflower, cotton, hazelnut, peanut, palm, and many others). A fast, inexpensive, and noninvasive method for checking the authenticity of oils is therefore desirable. Classical analytical methods were compared in a review, ${ }^{[113]}$ optical means, mass spectrometry, and NMR spectroscopy being among them.

$\mathrm{Xu}$ et al. ${ }^{[114]}$ used NMR mobile universal surface explorer to measure transverse relaxation and selfdiffusion on the oils with a spin echo pulse sequence in the static gradient. ${ }^{[92,115]}$ Olive oils with different concentrations of sunflower oil or red palm oil were investigated, exploring the capabilities of 2D ILT.

The analysis of olive oils within an intact bottle was performed by Santos et al. ${ }^{[116]}$ The transverse relaxation time $T_{2}$ of 37 different samples was determined by means of a LF-NMR spectrometer and an unilateral NMR sensor. PCA resulted in well-separated clusters of pure olive oil, pure soybean oil, and blends of both components. The LF-NMR measurements showed a better $S / N$ ratio, a clearer separation, and thus, a better distinguishability of the oils and therefore seem to be more suitable for wider use.

A large number of oils (anola, flax, grape seed, peanut, soybean, and sunflower seed oils) were mixed into olive oils, namely, olive oils with different oleoyl acyl contents, among them being Arbequina olive oil. ${ }^{[117]}$ The combination of LF-NMR relaxation and UV/VIS spectroscopy was able to provide evidence for adulteration. ${ }^{[117]} T_{2}$ values were determined by biexponential fits.

In addition to relaxation, adulterations of olive oil could also be detected by spectroscopy with a $60 \mathrm{MHz}$ benchtop spectrometer. ${ }^{[118,119]}$ The adulteration of olive oil with hazelnut oil was proven by chemometric data analysis of the ${ }^{1} \mathrm{H}$ spectra. The detection limit for hazelnut oil was at approximately $11 \% \mathrm{w} / \mathrm{w}$. Adulteration of EVOO with soybean oil ${ }^{[119]}$ was proven because EVOO 
is mainly composed of monounsaturated fatty acids. The signal intensities in the bis-allylic region in ${ }^{1} \mathrm{H}$ spectra (2.5 to $3.0 \mathrm{ppm}$ ) are significantly lower than in soybean oils, which mainly consist of the polyunsaturated fatty acid linoleic acid.

Other types of oil adulterations were also reported. Peanut oil, which is particularly popular in China, was mixed with soybean, rapeseed, or palm oil. ${ }^{[120]}$ By means of the LF-NMR measurement of transverse relaxation and subsequent data analysis via calculation of $T_{2}$ distributions and principal component analysis, adulterations were detected and quantified. Kim et al. ${ }^{[121]}$ could prove the adulteration of perilla oil with soybean oil ( $>6$ vol\%), which is widespread in Korea, by low-field spectroscopy at $43 \mathrm{MHz}$.

Some other cases are known in which used frying oil was added to vegetable oil that has been declared as fresh. ${ }^{[122]}$ The $T_{2}$ distribution served as an indicator for such adulterations.

\section{5 | CONCLUSION}

LF-NMR was proven to be a valuable tool for the characterization of oils (Table 1). Not only technical but also food oils were measured in the stages of raw oils, production, and refinement as well as during use. The diversity of this material class is complemented by the variety of LF-NMR methods on the analytical side, which makes the topic fascinating while being multifaceted. To name a few, relaxation properties mainly in form of transverse relaxation, diffusion, and spectroscopy were applied to characterize chemical composition (e.g., aging and saturation degree), physical states such as dispersion (e.g., droplet size determination) and molecular mobility (e.g., crystallinity). Pulse sequences and data processing were optimized for dedicated applications, for example, for measuring wet food or to provide 2D relaxation distributions. Further investigations are expected to explore LF spectroscopy, relaxation, and diffusion especially in terms of characterization of aging and adulteration but also during oil production and fabrication.

\section{ACKNOWLEDGMENTS}

This IGF Project of the FVA is supported via AiF within the programme for promoting the Industrial Collective Research (IGF) of the German Ministry of Economic Affairs and Energy (BMWi), based on a resolution of the German Parliament. The authors would like to thank the German Research Foundation (DFG) and ZIM for financial support. Especially Dr. F. Decker at Bruker is acknowledged for providing the LF 1H-1-D spectra of the aged motor oils.

\section{ORCID}

Thomas Rudszuck (D) https://orcid.org/0000-0003-2953-9627

Hermann Nirschl (D) https://orcid.org/0000-0001-6398-1692

Gisela Guthausen (D) https://orcid.org/0000-0002-6444-2663

\section{REFERENCES}

[1] B. Blümich, P. Blümler, G. Eidmann, A. Guthausen, R. Haken, U. Schmitz, K. Saito, G. Zimmer, Magn. Reson. Imaging 1998, 16, 479.

[2] T. W. Skloss, A. J. Kim, J. F. Haw, Anal. Chem. 1994, 66, 536.

[3] A. Nordon, A. Diez-Lazaro, C. W. L. Wong, C. A. McGill, D. Littlejohn, M. Weerasinghe, D. A. Mamman, M. L. Hitchman, J. Wilkie, Analyst 2008, 133, 339.

[4] C. A. McGill, R. H. Ferguson, K. Donoghue, A. Nordon, D. Littlejohn, Analyst 2003, 128, 1467.

[5] G. Guthausen, A. Kamlowski, in Magnetic Resonance in Food Science: Challenges in a Changing World, (Eds: M. Guojonsdottir, P. Belton, G. A. Webb) Vol. 293, RSC Publisher, Nordic House, Reykjavik, Iceland 200946.

[6] M. A. Vargas, M. Cudaj, K. Hailu, K. Sachsenheimer, G. Guthausen, Macromolecules 2010, 43, 5561.

[7] M. Cudaj, G. Guthausen, T. Hofe, M. Wilhelm, Macromol. Rapid Commun. 2011, 32, 665.

[8] F. Dalitz, M. Cudaj, M. Maiwald, G. Guthausen, Prog. Nucl. Magn. Reson. Spectrosc. 2012, 60, 52.

[9] G. Guthausen, A. von Garnier, R. Reimert, Appl. Spectrosc. 2009, 63, 1121.

[10] Y. G. Linck, M. H. M. Killner, E. Danieli, B. Blümich, Appl. Magn. Reson. 2013, 44, 41.

[11] S. K. Küster, F. Casanova, E. Danieli, B. Blümich, Phys. Chem. Chem. Phys. 2011, 13, 13172.

[12] E. Danieli, J. Perlo, B. Blümich, F. Casanova, Angew. Chem. Int. Ed. 2010, 49, 4133.

[13] N. Zientek, C. Laurain, K. Meyer, A. Paul, D. Engel, G. Guthausen, M. Kraume, M. Maiwald, Magn. Reson. Chem. 2016, 54, 513.

[14] N. Zientek, C. Laurain, K. Meyer, M. Kraume, G. Guthausen, M. Maiwald, J. Magn. Reson. 2014, 249, 53.

[15] R. L. Kleinberg, A. Sezginer, D. D. Griffin, M. Fukuhara, J. Magn. Reson. 1992, 97, 466.

[16] P. P. Mitra, P. N. Sen, Phys. Rev. B 1992, 45, 143.

[17] P. P. Mitra, P. N. Sen, L. M. Schwartz, Phys. Rev. B 1993, 47, 8565.

[18] L. L. Latour, P. P. Mitra, R. L. Kleinberg, C. H. Sotak, J. Magn. Reson. Ser. A 1993, 101, 342.

[19] M. D. Hürlimann, L. Venkataramanan, J. Magn. Reson. 2002, $157,31$.

[20] D. E. Freed, M. D. Hürlimann, U. M. Scheven, J. Magn. Reson. 2003, 162, 328.

[21] Y. Q. Song, M. D. Hürlimann, C. Flaum, J. Magn. Reson. 2003, $161,222$.

[22] M. D. Hürlimann, J. Magn. Reson. 2007, 184, 114.

[23] V. Anand, G. J. Hirasaki, J. Magn. Reson. 2008, 190, 68. 
[24] J. H. Ortony, C. Y. Cheng, J. M. Franck, R. Kausik, A. Pavlova, J. Hunt, S. I. Han, New J. Phys. 2011, 13.

[25] Y. Q. Song, J. Magn. Reson. 2013, 229, 12.

[26] J. Mitchell, L. F. Gladden, T. C. Chandrasekera, E. J. Fordham, Prog. Nucl. Magn. Reson. Spectrosc. 2014, 76, 1.

[27] A. Lala, N. A. E. El-Sayed, Arab. J. Geosci. 2015, 8, 7955.

[28] J. Mitchell, A. M. Howe, A. Clarke, J. Magn. Reson. 2015, 256, 34.

[29] L. Venkataramanan, F. K. Gruber, J. LaVigne, T. M. Habashy, J. G. Iglesias, P. Cohorn, V. Anand, M. A. Rampurawala, V. Jain, N. Heaton, R. Akkurt, E. Rylander, R. Lewis, Petrophysics 2015, 56, 147.

[30] S. Stapf, A. Ordikhani-Seyedlar, C. Mattea, R. Kausik, D. E. Freed, Y. Q. Song, M. D. Hürlimann, Microporous Mesoporous Mater. 2015, 205, 56.

[31] G. F. Carneiro, R. C. Silva, L. L. Barbosa, J. C. C. Freitas, C. M. S. Sad, L. V. Tose, B. G. Vaz, W. Romao, E. V. R. de Castro, A. C. Neto, V. Lacerda, Fuel 2015, 140, 762.

[32] G. A. LaTorraca, K. J. Dunn, P. R. Webber, R. M. Carlson, Magn. Reson. Imaging 1998, 16, 659.

[33] M. Hürlimann, D. Griffin, J. Magn. Reson. 2000, 143, 120.

[34] B. Blümich, F. Casanova, J. Perlo, S. Anferova, V. Anferov, K. Kremer, N. Goga, K. Kupferschläger, M. Adams, Magn. Reson. Imaging 2005, 23, 197.

[35] C. H. Arns, K. E. Washburn, P. T. Callaghan, Petrophysics 2007, 48, 380 .

[36] L. B. Casabianca, D. Mohr, S. Mandal, Y.-Q. Song, L. Frydman, J. Magn. Reson. 2014, 242, 197.

[37] H. Xu, D. Z. Tang, J. L. Zhao, S. Li, Fuel 2015, 143, 47.

[38] X. M. Ge, Y. R. Fan, H. Chen, S. G. Deng, Y. C. Cao, M. A. Zahid, J. Magn. Reson. 2015, 260, 54.

[39] Y. Zhang, L. Z. Xiao, G. Z. Liao, B. Blümich, J. Magn. Reson. 2016, 267, 37.

[40] L. L. Barbosa, F. V. C. Kock, V. M. D. L. Almeida, S. M. C. Menezes, E. V. R. Castro, Fuel Process. Technol. 2015, 138, 202.

[41] L. C. L. Barbosa, C. M. Sad, V. G. Morgan, M. F. Santos, E. Q. V. Castro, Energy Fuel 2013, 27, 6560.

[42] A. Muhammad, R. B. D. V. Azeredo, Fuel 2014, 130, 126.

[43] A. A. Pena, G. J. Hirasaki, Adv. Colloid Interf. Sci. 2003, 105, 103.

[44] A. G. Marshall, R. P. Rodgers, Acc. Chem. Res. 2004, 37, 53.

[45] R. A. Prestes, L. A. Colnago, L. A. Forato, L. Vizzotto, E. H. Novotny, E. Carrilho, Anal. Chim. Acta 2007, 596, 325.

[46] T. F. Conway, F. R. Earle, J. Am. Oil Chem. Soc. 1963, 40, 265.

[47] P. N. Tiwari, P. N. Gambhir, T. S. Rajan, J. Am. Oil Chem. Soc. 1974, 51, 104.

[48] P. N. Tiwari, W. Burk, J. Am. Oil Chem. Soc. 1980, 57, 119.

[49] P. N. Gambhir, Trends Food Sci. Technol. 1992, 3, 191.

[50] G. Rubel, J. Am. Oil Chem. Soc. 1994, 71, 1057.

[51] J. Fuchs, T. Neuberger, H. Rolletschek, S. Schiebold, T. H. Nguyen, N. Borisjuk, A. Börner, G. Melkus, P. Jakob, L. Borisjuk, Plant Physiol. 2013, 161, 583.

[52] E. Veliyulin, C. van der Zwaag, W. Burk, U. Erikson, J. Sci. Food Agric. 2005, 85, 1299.
[53] A. S. O. T. A. Measurements, Vol. ASTM / D 3701-01, ASTM/D 4808-01, ASTM/D7171-05.

[54] M. H. M. Killner, Y. G. Linck, E. Danieli, J. J. R. Rohwedder, B. Blümich, Fuel 2015, 139, 240.

[55] L. F. Cabeca, L. V. Marconcini, G. P. Mambrini, R. B. V. Azeredo, L. A. Colnago, Energy Fuel 2011, 25, 2696.

[56] P. Berman, N. Meiri, L. A. Colnago, T. B. Moraes, C. Linder, O. Levi, Y. Parmet, M. Saunders, Z. Wiesman, Biotechnol Biofuels 2015, 8.

[57] N. Meiri, P. Berman, L. A. Colnago, T. B. Moraes, C. Linder, Z. Wiesman, Biotechnol Biofuels 2015, 8.

[58] D. A. Cunha, L. F. Montes, E. V. R. Castro, L. L. Barbosa, Fuel 2016, 166, 79.

[59] Z. P. Zhong, X. X. Jiang, N. Ellis, Korean J. Chem. Eng. 2011, $28,133$.

[60] H. X. Ben, A. J. Ragauskas, Energy Fuel 2011, 25, 2322.

[61] F. Dalitz, A. Steiwand, K. Raffelt, H. Nirschl, G. Guthausen, Energy Fuel 2012, 26, 5274.

[62] K. P. Van Putte, J. Van den Enden, J. Phys. E: Sci. Instrum. 1973, 6, 910.

[63] W. D. Pohle, R. L. Gregory, J. Am. Oil Chem. Soc. 1968, 45, 775.

[64] W. A. Bosin, R. A. Marmor, J. Am. Oil Chem. Soc. 1968, 45, 335.

[65] K. P. Van Putte, J. Van den Enden, J. Am. Oil Chem. Soc. 1974, 51, 316.

[66] E. Standard, Vol. ISO8292-1, Ethiopian Standard, 2012.

[67] E. Standard, Vol. ISO8292-2, Ethiopian Standard, 2012.

[68] I. O. F. Standardization, Vol. ISO 8292, 1991.

[69] A. O. C. Society, ed., Am. Oil Chem. Soc., 2009.

[70] J. C. V. Enden, A. J. Haighton, K. van Putte, L. F. Vermaas, D. Waddington, Anstrichmittel 1978, 80, 180.

[71] J. C. van den Enden, J. B. Rossell, L. F. Vermaas, D. Waddington, J. Am. Oil Chem. Soc. 1982, 59, 433.

[72] J. van Duynhoven, I. Dubourg, G. J. Goudappel, E. Roijers, J. Am. Oil Chem. Soc. 2002, 79, 383.

[73] A. Declerck, V. Nelis, T. Rimaux, K. Dewettinck, P. Van der Meeren, Eur. J. Lipid Sci. Technol. 2018, 120, 1700339.

[74] E. Trezza, A. M. Haiduc, G. J. W. Goudappel, J. P. M. van Duynhoven, Magn. Reson. Chem. 2006, 44, 1023.

[75] F. P. Duval, J. P. M. van Duynhoven, A. Bot, J. Am. Oil Chem. Soc. 2006, 83, 905.

[76] S. S. Narine, K. L. Humphrey, J. Am. Oil Chem. Soc. 2004, 81, 101.

[77] G. Mazzanti, E. M. Mudge, E. Y. Anom, J. Am. Oil Chem. Soc. 2008, 85, 405.

[78] C. Linke, G. Guthausen, E. Flöter, S. Drusch, Eur. J. Lipid Sci. Technol. 2018, 1700132, 1.

[79] J. S. Murday, R. M. Cotts, J. Chem. Phys. 1968, 48, 4938.

[80] K. J. Packer, D. J. Tomlinso, C. Rees, Adv. Mol. Relax. Process. 1972, 3, 119.

[81] P. S. Denkova, S. Tcholakova, N. D. Denkov, K. D. Danov, B. Campbell, C. Shawl, D. Kim, Langmuir 2004, 20, 11402. 
[82] W. Fieber, V. Hafner, V. Normand, J. Colloid Interface Sci. 2011, 356, 422.

[83] K. G. Hollingsworth, M. L. Johns, J. Colloid Interface Sci. 2003, $258,383$.

[84] T. Garasanin, T. Cosgrove, L. Marteaux, A. Kretschmer, A. Goodwin, K. Zick, Langmuir 2002, 18, 10298.

[85] J. H. Sommerling, A. J. Simon, A. Haber, M. L. Johns, G. Guthausen, H. Nirschl, in Proceedings of the XIII International Conference on the Applications of Magnetic Resonance in Food Science, (Eds: J. van Duynhoven, G. Guthausen), Chichester, West Sussex: IM Publications 201667.

[86] R. Bernewitz, F. Dalitz, K. Köhler, H. P. Schuchmann, G. Guthausen, Microporous Mesoporous Mater. 2013, 178, 69.

[87] R. Bernewitz, U. S. Schmidt, H. P. Schuchmann, G. Guthausen, Colloids Surf. A Physicochem. Eng. Asp. 2014, 458, 10.

[88] L. Vermeir, M. Balcaen, P. Sabatino, K. Dewettinck, P. Van der Meeren, Colloids Surf. A Physicochem. Eng. Asp. 2014, 456, 129.

[89] L. Vermeir, P. Sabatino, M. Balcaen, A. Declerck, K. Dewettinck, J. C. Martins, G. Guthausen, P. Van der Meeren, J. Colloid Interface Sci. 2016, 475, 57.

[90] A. Guthausen, G. Guthausen, A. Kamlowski, H. Todt, W. Burk, D. Schmalbein, J. Am. Oil Chem. Soc. 2004, 81, 727.

[91] A. M. Haiduc, E. E. Trezza, D. van Dusschoten, A. A. Reszka, J. P. M. van Duynhoven, LWT 2007, 40, 737.

[92] G. Guthausen, A. Guthausen, F. Balibanu, R. Eymael, K. Hailu, U. Schmitz, B. Blümich, Macromol. Mater. Eng. 2000, 276, 25.

[93] H. T. Pedersen, S. Ablett, D. R. Martin, M. J. D. Mallett, S. B. Engelsen, J. Magn. Reson. 2003, 165, 49.

[94] E. O. Stejskal, J. E. Tanner, J. Chem. Phys. 1965, 42, 288.

[95] M. Ballari, F. Bonetto, E. Anoardo, J. Phys. D. Appl. Phys. 2005, 38, 3746.

[96] E. Förster, H. Nirschl, G. Guthausen, Appl. Magn. Reson. 2017, 48, 51.

[97] P. Berman, N. Meiri, C. Linder, Z. Wiesman, Fuel 2016, 177, 315.

[98] G. Guthausen, J. König, A. Kamlowski, Spin Rep 2004, 154, 41.

[99] M. Adam-Berret, M. Boulard, A. Riaublanc, F. Mariette, J. Agric. Food Chem. 2011, 59, 1767.

[100] M. Adam-Berret, A. Riaublanc, C. Rondeau-Mouro, F. Mariette, Cryst. Growth Des. 2009, 9, 4273.

[101] M. Adam-Berret, C. Rondeau-Mouro, A. Riaublanc, F. Mariette, Magn. Reson. Chem. 2008, 46, 550.

[102] P. Conte, A. Maccotta, C. D. Pasquale, G. Alonzo, Fresenius Environ. Bull. 2010, 19, 2077.

[103] M. L. Herrera, J. I. M'Cann, C. Ferrero, T. Hagiwara, N. E. Zaritzky, R. W. Hartel, Food Biophys. 2007, 2, 20.

[104] A. Gerdova, M. Defernez, W. Jakes, E. Limer, C. McCallum, K. Nott, T. Parker, N. Rigby, A. Sagidullin, A. D. Watson, D. Williamson, E. K. Kemsley, in Magnetic Resonance in Food Science: Defining Food by Magnetic Resonance, (Eds: L. L. F. Capozzi, P. S. Belton) London: Royal Society of Chemistry 201517
[105] W. Jakes, A. Gerdova, M. Defernez, A. D. Watson, C. McCallum, E. Limer, I. J. Colquhoun, D. C. Williamson, E. K. Kemsley, Food Chem. 2015, 175, 1.

[106] P. A. M. Nascimento, P. L. Barsanelli, A. P. Rebellato, J. A. L. Pallone, L. A. Colnago, F. M. V. Pereira, J. AOAC Int. 2017, 100, 330.

[107] R. E. Hester, D. E. C. Quine, J. Dairy Res. 2009, 44, 125.

[108] E. Veliyulin, I. V. Mastikhin, A. E. Marble, B. J. Balcom, J. Sci. Food Agric. 2008, 88, 2563.

[109] B. Chaland, F. Mariette, P. Marchal, J. De Certaines, J. Dairy Res. 2001, 67, 609.

[110] T. Lucas, F. Mariette, S. Dominiawsyk, D. Le Ray, Food Chem. 2004, 84, 77.

[111] H. Hickey, B. MacMillan, B. Newling, M. Ramesh, P. Van Eijck, B. Balcom, Food Res. Int. 2006, 39, 612.

[112] B. Gouilleux, J. Marchand, B. Charrier, G. S. Remaud, P. Giraudeau, Food Chem. 2018, 244, 153.

[113] D. I. Ellis, V. L. Brewster, W. B. Dunn, J. W. Allwood, A. P. Golovanov, R. Goodacre, Chem. Soc. Rev. 2012, 41, 5706.

[114] Z. Xu, R. Morris, M. Bencsik, M. Newton, Sensors 2014, 14, 2028.

[115] D. G. Rata, F. Casanova, J. Perlo, D. E. Demco, B. Blümich, J. Magn. Reson. 2006, 180, 229.

[116] P. M. Santos, F. V. C. Kock, M. S. Santos, C. M. S. Lobo, A. S Carvalho, L. A. Colnago, J. Braz. Chem. Soc. 2017, 28, 385.

[117] S. Ok, Grasas Aceites 2017, 68, 173.

[118] T. Parker, E. Limer, A. D. Watson, M. Defernez, D. Williamson, E. Kate Kemsley, TrAC Trends Anal. Chem. 2014, 57, 147.

[119] S. Riegel, Am. Lab. 2015, 47, 16.

[120] W. Zhu, X. Wang, L. Chen, Food Chem. 2017, 216, 268.

[121] J. H. Kim, H. J. Lee, K. Kwon, H. S. Chun, S. Ahn, B. H. Kim, J. Oleo Sci. 2018, 67, 507.

[122] Q. Zhang, A. S. M. Saleh, Q. Shen, Food Bioprocess Technol. 2013, 6, 2562.

[123] X. Hu, S. Hu, F. Jin, S. Huang, Physics of petroleum reservoirs, Berlin: Springer 2017.

[124] T. Mang, W. Dresel, Lubricants and lubrications, Wiley-VCH, Weinheim, New York; Chichester 2001.

[125] G. E. Totten, S. R. Westbrook, R. J. Shah, Fuels and lubricants handbook: technology, properties, performance, and testing, ASTM International, West Conshohocken, PA 2003.

[126] W. J. Bartz, Additive für Schmierstoffe, Expert-Verlag, 1994.

[127] W. J. Bartz, Wear 1978, 49, 1.

[128] A. C. Pinto, L. L. Guarieiro, M. J. Rezende, N. M. Ribeiro, E. A. Torres, W. A. Lopes, P. A. D. P. Pereira, J. B. D. Andrade, J. Braz. Chem. Soc. 2005, 16, 1313.

[129] G. Knothe, Fuel Process. Technol. 2005, 86, 1059.

[130] OECD, Food, A. O. O. T. U. Nations, OECD-FAO Agricultural Outlook 2016-2025, 2016.

[131] B. Petersson, K. Anjou, L. Sandström, Anstrichmittel 1985, 87, 225.

[132] M. C. M. Gribnau, Trends Food Sci. Technol. 1992, 31, 186.

[133] A. O. C. Society, Vol. AOCS Official Method Cd 16b-93, Cd 16-81, AOCS, 1993. 
[134] A. O. C. Society, Cd 16b 93 ed., American Oil Chemists Society, 1997.

[135] H. Todt, W. Burk, G. Guthausen, A. Guthausen, A. Kamlowski, D. Schmalbein, Eur. J. Lipid Sci. Technol. 2001, 103, 835.

[136] F. Bloch, Phys. Rev. 1946, 70, 460.

[137] S. W. Provencher, Comput. Phys. Commun. 1982, 27, 229.

[138] P. T. Callaghan, C. H. Arns, P. Galvosas, M. W. Hunter, Y. Qiao, K. E. Washburn, Magn. Reson. Imaging 2007, 25, 441.

[139] Y.-Q. Song, L. Venkataramanan, L. Burcaw, J. Chem. Phys. 2005, 122, 104104.

[140] Z. Wiesman, C. Linder, M. T. Resende, N. Ayalon, O. Levi, O. D. Bernardinelli, L. A. Colnago, C. I. N. Mitre, R. Jackman, Energy Fuel 2018, 32, 5090.

[141] P. Berman, O. Levi, Y. Parmet, M. Saunders, Z. Wiesman, Concepts Magn Reson Part A 2013, 42, 72.

[142] M. Röding, D. Bernin, J. Jonasson, A. Sarkka, D. Topgaard, M. Rudemo, M. Nyden, J. Magn. Reson. 2012, 222, 105.

[143] R. Bernewitz, G. Guthausen, H. P. Schuchmann, Magn. Reson. Chem. 2011, 49, S93.

[144] K. J. Packer, C. Rees, J. Colloid Interface Sci. 1972, 40, 206.

[145] G. J. W. Goudappel, J. P. M. van Duynhoven, M. M. W. Mooren, J. Colloid Interface Sci. 2001, 239, 535.

[146] J. P. M. van Duynhoven, G. J. W. Goudappel, G. van Dalen, P. C. van Bruggen, J. C. G. Blonk, A. P. A. M. Eukelenboom, Magn. Reson. Chem. 2002, 40, S51.

[147] J. P. M. van Duynhoven, B. Maillet, J. Schell, M. Tronquet, G. J. W. Goudappel, E. Trezza, A. Bulbarello, D. van Dusschoten, Eur. J. Lipid Sci. Technol. 2007, 109, 1095.

[148] N. F. Ramsey, E. M. Purcell, Phys. Rev. 1952, 85, 143.

[149] N. Bloembergen, E. M. Purcell, R. V. Pound, Phys. Rev. 1948, 73, 679 .

[150] A. Abragam, The principles of nuclear magnetism, Oxford, UK: Oxford University Press 1961.

[151] R. M. Steele, J. P. Korb, G. Ferrante, S. Bubici, Magn. Reson. Chem. 2016, 54, 502.

[152] E. Gianolio, G. B. Giovenzana, D. Longo, I. Longo, I. Menegotto, S. Aime, Chem. Eur. J. 2007, 13, 5785.

[153] J. P. Korb, New J. Phys. 2011, 13, 035016.

[154] L. F. N. spectrometer, 2015.

[155] A. Nordon, C. A. McGill, D. Littlejohn, Analyst 2001, 126, 260.

[156] B. Gouilleux, B. Charrier, S. Akoka, F.-X. Felpin, M. Rodriguez-Zubiri, P. Giraudeau, TrAC Trends Anal. Chem. 2016, 83, 65 .

[157] A. Aimin, H. Xiaohong, S. Hongye, in 2008 IEEE International Conference on Automation and Logistics, 2008, pp. 7.

[158] L. L. Barbosa, C. M. S. Sad, V. G. Morgan, P. R. Figueiras, E. R. V. Castro, Fuel 2016, 176, 146.

[159] L. L. Barbosa, F. V. C. Kock, R. C. Silva, J. C. C. Freitas, V. Lacerda, E. V. R. Castro, Energy Fuel 2013, 27, 673.

[160] J. P. Korb, N. Vorapalawut, B. Nicot, R. G. Bryant, J. Phys. Chem. C 2015, 119, 24439.

[161] ISO, AOCS Recommended Practice Ak 4-95, 2017.
[162] E. Brosio, F. Conti, A. di Nola, O. Scorano, F. Balestrieri, Int. J. Food Sci. Technol. 1981, 16, 629.

[163] V. T. Srinivasan, J. Am. Oil Chem. Soc. 1979, 56, 1000.

[164] Bruker, Application Note 2017, 1.

[165] A. O. C. Society, 1995.

[166] I. O. F. Standardization, Vol. ISO/CD 10632, 1993.

[167] I. O. F. Standardization, Vol. ISO 10565, 1995.

[168] T. Ram, Z. Wiesman, I. Parmet, Y. Edan, Biosyst. Eng. 2010, 105, 221.

[169] H. T. Pedersen, L. Munck, S. B. Engelsen, J. Am. Oil Chem. Soc. 2000, 77, 1069.

[170] A. D. Weir, J. Omielan, E. A. Lee, I. Rajcan, J. Am. Oil Chem. Soc. 2005, 82, 87.

[171] P. J. Horn, P. Neogi, X. Tombokan, S. Ghosh, B. T. Campbell, K. D. Chapman, J. Am. Oil Chem. Soc. 2011, 88, 1521.

[172] F. C. Tinsley, G. Z. Taicher, M. L. Heiman, Obes. Res. 2001, 9, 150.

[173] F. C. Tinsley, G. Z. Taicher, M. L. Heiman, Obes. Res. 2004, 12, 150.

[174] T. Rudi, G. Guthausen, W. Burk, C. T. Reh, H. D. Isengard, Food Chem. 2008, 106, 1375.

[175] L. A. Colnago, R. B. V. Azeredo, A. M. Netto, F. D. Andrade, T. Venancio, Magn. Reson. Chem. 2011, 49, S113.

[176] R. B. D. Azeredo, L. A. Colnago, M. Engelsberg, Anal. Chem. 2000, 72, 2401.

[177] H. Rolletschek, J. Fuchs, S. Friedel, A. Borner, H. Todt, P. M. Jakob, L. Borisjuk, Plant Biotechnol. J. 2015, 13, 188.

[178] J. Vanhanen, M. Rinkio, J. Aumanen, J. Korppi-Tommola, E. Kolehmainen, T. Kerkkanen, P. Torma, Appl. Opt. 2004, 43, 4718.

[179] F. R. van de Voort, J. Sedman, R. Cocciardi, S. Juneau, Talanta 2007, 72, 289.

[180] J. Zięba-Palus, P. Kościelniak, M. Łącki, Forensic Sci. Int. 2001, 122, 35.

[181] E. Förster, C. C. Fraenza, J. Küstner, E. Anoardo, H. Nirschl, G. Guthausen, Measurement 2019, 137, 673.

[182] E. Förster, J. Becker, F. Dalitz, B. Görling, B. Luy, H. Nirschl, G. Guthausen, Energy Fuel 2015, 29, 7204.

[183] A. Kupareva, P. Mäki-Arvela, H. Grénman, K. Eränen, R. Sjöholm, M. Reunanen, D. Y. Murzin, Energy Fuel 2013, 27, 27.

[184] E. Dominguez-Rosado, J. Pichtel, Proc. Indiana Acad. Sci. 2003, 112, 109.

[185] V. Bansal, K. C. Dohhen, R. Sarin, A. S. Sarpal, A. K. Bhatnagar, Tribol. Int. 2002, 35, 819.

How to cite this article: Rudszuck T, Förster E, Nirschl H, Guthausen G. Low-field NMR for quality control on oils. Magn Reson Chem. 2019;1-17. https://doi.org/10.1002/mrc.4856 